\title{
THE TECHNIQUES OF OPERATIONAL AND INVESTIGATIVE COUNTERING ACTIONS AGAINST EXTREMIST CRIMES BY THE OPERATIONAL UNITS OF THE INTERNAL AFFAIRS BODIES
}

\author{
Elena N. Kholopova \\ Immanuel Kant Baltic Federal University, Kaliningrad, Russian Federation
}

Yulia O. Kopchenkova

Saint Petersburg University of the Ministry of Internal Affairs of the Russian Federation, Saint Petersburg, Russian Federation

\begin{abstract}
Introduction: the counteraction to crimes of extremist orientation is carried out by the operational divisions of the Internal Affairs Bodies that need the techniques of counteraction to such crimes, which is confirmed by the results of the empirical research. The development of the basic techniques for operational and investigative counteraction to extremist crimes is determined by: improving the activities of the operational units, improving the quality of interaction between the police and other state bodies, religious and public associations on counteraction issues; a comprehensive approach to counteraction depending on the type of extremism and the operational situation in the region. The purpose of the study was to develop the basics of the operational investigative counteraction techniques using a situational approach. Methods: the methodological framework for this research is a set of methods of scientific knowledge, among which the main ones are the methods of systematicity, analysis and situational approach. Results: the paper considers the possibility of using the situational approach to the basics of the techniques for countering extremist crimes, substantiates the authors' position on various characteristics of the structural and content elements of the techniques, the sources of recommendations, which are the operational-search characteristics of extremist crimes, operational-search practice and science. Conclusions: the identification and description of real typical situations of counteraction in which operational officers of the Internal Affairs bodies have to act is an important condition for the development of specific methodological recommendations. The following structural and substantive elements of the techniques for countering extremist crimes are highlighted (blocks of recommendations): recommendations on legal support of counteraction; recommendations on application of the operational and preventive measures; recommendations on interaction with the subjects of counteraction to extremism; recommendations on the operational situation in the region for extremist crimes; recommendations on the use of the information sources.
\end{abstract}

Key words: operational-search counteraction to crimes of extremism, methods of counteraction, recommendations, crimes of extremist orientation, situational approach.

Citation. Kholopova E.N., Kopchenkova Yu.O. The Techniques of Operational and Investigative Countering Actions Against Extremist Crimes by the Operational Units of the Internal Affairs Bodies. Legal Concept, 2020, vol. 19, no. 2, pp. 35-42. (in Russian). DOI: https://doi.org/10.15688/lc.jvolsu.2020.2.5

\section{МЕТОДИКА ОПЕРАТИВНО-РОЗЫСКНОГО ПРОТИВОДЕЙСТВИЯ ПРЕСТУПЛЕНИЯМ ЭКСТРЕМИСТСКОЙ НАПРАВЛЕННОСТИ ОПЕРАТИВНЫМИ ПОДРАЗДЕЛЕНИЯМИ ОРГАНОВ ВНУТРЕННИХ ДЕЛ}

\author{
Елена Николаевна Холопова \\ Балтийский федеральный университет им. И. Канта, \\ г. Калининград, Российская Федерация
}




\section{Юлия Олеговна Копченкова}

Санкт-Петербургский университет Министерства внутренних дел Российской Федерации, г. Санкт-Петербург, Российская Федерация

Введение: противодействие преступлениям экстремистской направленности осуществляется оперативными подразделениями органов внутренних дел, которые нуждаются в методике противодействия таким преступлениям, что подтверждается результатами эмпирических исследований. Разработка основ методики оперативно-розыскного противодействия преступлениям экстремистской направленности определяется: совершенствованием деятельности оперативных подразделений, повышением качества взаимодействия органов полиции с иными государственными органами, религиозными и общественными объединениями по вопросам противодействия; комплексным подходом к противодействию в зависимости от вида экстремизма и оперативной обстановки в регионе. Цель исследования заключалась в разработке основ методики оперативно-розыскного противодействия с использованием ситуационного подхода. Методы: методологическую основу данного исследования составляет совокупность методов научного познания, среди которых основное место занимают методы системности, анализа и ситуационный подход. Результаты: в работе рассматривается возможность использования ситуационного подхода к основам методики противодействия преступлениям экстремистской направленности, обосновывается авторская позиция к различным характеристикам структурно-содержательных элементов методики, источникам рекомендаций, которыми являются оперативно-розыскная характеристика преступлений экстремистской направленности, оперативно-розыскная практика и наука. Выводы: выделение и описание реальных типовых ситуаций противодействия, в которых приходится действовать оперативным сотрудникам органов внутренних дел является важным условием разработки конкретных методических рекомендаций. Выделены следующие структурно-содержательные элементы методики противодействия преступлениям экстремистской направленности (блоки рекомендаций): рекомендации по правовому обеспечению противодействия; рекомендации по применению оперативно-профилактических мер; рекомендации по взаимодействию с субъектами противодействия экстремизму; рекомендации по оперативной обстановке в регионе по преступлениям экстремистской направленности; рекомендации об использовании источников информации.

Ключевые слова: оперативно-розыскное противодействие преступлениям экстремистской направленности, методика противодействия, рекомендации, преступления экстремистской направленности, ситуационный подход.

Цитирование. Холопова Е. Н., Копченкова Ю. О. Методика оперативно-розыскного противодействия преступлениям экстремистской направленности оперативными подразделениями органов внутренних дел // Legal Concept = Правовая парадигма. - 2020. - T. 19, № 2. - C. 35-42. - DOI: https://doi.org/10.15688/ lc.jvolsu.2020.2.5

\section{Введение}

Преступления экстремистской направленности (далее - ПЭН) являются лишь небольшой частью от общего числа преступлений. При этом повышенная общественная опасность приводит к необходимости причисления указанных преступлений к одному из важнейших угроз национальной безопасности России $(0,06 \%$ в 2015 г., по $0,07 \%$ в 2016 и 2017 гг., в 2018 г. и 2019 г. наметился спад доли выявленных ПЭН по отношению к зарегистрированной преступности в России по АППГ в 2018 на $0,01 \%$, в 2019 г. - на $0,04 \%$ и составляет $0,02 \%$ от общего количества зарегистрированных преступлений) [5]. Уменьшение числа зарегистрированных ПЭН объясняется как внесенными в УК РФ изменения- ми в части установления дополнительных условий для привлечения к уголовной ответственности за совершения преступлений, предусмотренных ст. 282 УК РФ, так и профилактикой данных преступлений органами внутренних дел, иными общественными и государственными организациями. Однако, даже с учетом незначительной доли ПЭН относительно зарегистрированных преступлений в России, они обладают высокой общественной опасностью, при их совершении создается угроза государственной и общественной безопасности Российской Федерации, ее территориальной целостности, суверенитету и гражданскому единству. Результаты анализа противодействия ПЭН оперативными подразделениями органов внутренних дел свидетельствуют о необходимости и научной обоснован- 
ности разработки методики оперативно-розыскного противодействия. Актуальность разработки такой методики подтверждается: необходимостью совершенствования деятельности оперативных подразделений по противодействию ПЭН в зависимости от места их совершения; сбором и систематизацией информации о деятельности общественных объединений экстремистской направленности (с учетом которой предпринимать меры индивидуального профилактического воздействия в отношении лидеров и активных участников формирований); результатами проведения мониторинга деятельности средств массовой информации (в том числе в сети Интернет) на предмет выявления распространения материалов экстремистской направленности; повышением качества взаимодействия оперативных подразделений органов внутренних дел с органами государственной власти и органами местного самоуправления по вопросам противодействия ПЭН; комплексным подходом к противодействию в зависимости от вида экстремизма и оперативной обстановки в регионе.

Результаты исследований, касающиеся проблем оперативно-розыскных методик, в том числе и по ПЭН, свидетельствуют об: отсутствии общепринятых методологических основ их разработки; обоснованности понятий таких методик; различных характеристиках структурно-содержательных элементов ПЭН. Обоснование методики противодействия ПЭН определяется исследованием правовых, теоретических и практических аспектов, то есть источниками рекомендаций, которыми являются оперативно-розыскная характеристика ПЭН, оперативно-розыскная практика и наука.

\section{Рекомендации \\ по противодействию преступлениям экстремистской направленности}

Федеральный закон «О противодействии экстремистской деятельности» № 114-ФЗ определяет ее основные направления: принятие профилактических мер, направленных на предупреждение экстремистской деятельности, в том числе на выявление и последующее устранение причин и условий, способствующих осуществлению экстремистской деятельнос- ти; выявление, предупреждение и пресечение экстремистской деятельности общественных и религиозных объединений, иных организаций, физических лиц. Исходя из выделенных направлений к числу важных проблем, связанных с созданием частных методик противодействия, следует отнести проблему выделения в этих методиках блоков рекомендаций, разработка которых целесообразна на основе ситуационного подхода [1, с. 263]. Иными словами, такие рекомендации необходимо привязывать к ситуациям противодействия по ПЭН, к направлениям, выделенным в законе.

Методика оперативно-розыскного противодействия преступлениям экстремистской направленности - это система научных положений и рекомендаций по организации эффективного применения оперативно-розыскных сил, средств и методов для своевременного выявления, документирования, предупреждения и раскрытия преступлений, а также лиц, их подготавливающих, совершающих, совершивших с учетом складывающихся ситуаций и оперативной обстановки в регионе.

Выделение и описание реальных типовых ситуаций противодействия, в которых приходится действовать оперативным сотрудникам, является важным условием разработки конкретных методических рекомендаций. Типовые ситуации противодействия должны иметь соответствующие направления рекомендаций.

Полагаем, что к таким рекомендациям необходимо отнести следующие:

1. Рекомендации по правовому обеспечению противодействия ПЭН. Такие рекомендации следует разрабатывать исходя из ситуаций, связанных с использованием оперативным сотрудником нормативных актов различных уровней: международных правовых актов, федеральных законов и иных актов органов государственной власти; ведомственных и межведомственных правовых актов.

Исходя из первой ситуации, оперативному сотруднику необходимы знания и умения применения следующих федеральных законов: Федерального закона «О противодействии экстремистской деятельности» от 25 июля 2002 г. № 114-Ф3 в части познания основных понятий экстремистской деятельности, правовых и основных организационных форм противодействия экстремистской деятельности, 
а также ответственности; Федерального закона «Об оперативно-розыскной деятельности» от 12 августа 1995 г. № 144-ФЗ в части знания оснований, условий и порядка проведения оперативно-розыскных мероприятий, порядка осуществления содействия гражданами органам внутренних дел; Федерального закона «О полиции» от 07 февраля 2011 г. № 3-Ф3 в части отнесения к основным обязанностям полиции противодействия экстремизму и другие. Также сложности возникают при соответствующем отнесении преступлений к категории ПЭН. Данное в УК РФ понятие «преступлений экстремистской направленности» при его фактическом толковании может включать в себя любое преступление, предусмотренное особенной частью УК РФ, совершенное по так называемому экстремистскому мотиву - «политической, идеологической, расовой, национальной или религиозной ненависти или вражды либо ненависти или вражды в отношении какой-либо социальной группы» [6]. Однако фактически к преступлениям экстремистской направленности относят небольшой список преступлений, предусмотренный перечнем статей УК РФ, используемых при формировании статистической отчетности, утвержденный указанием Генпрокуратурой России и МВД России от 27 декабря 2017 года.

Исходя из второй ситуации, оперативному сотруднику необходимы знания ведомственных и межведомственных нормативных правовых актов, определяющих особенности проведения отдельных оперативно-розыскных мероприятий (далее - ОРМ), действий, операций при раскрытии ПЭН. В связи с повышенной общественной опасностью ПЭН в МВД России в соответствии с Указом Президента России от 06 сентября 2008 г. № 1316 образованы и по настоящее время функционируют оперативные подразделения по противодействию экстремизму, на которых непосредственно возложена обязанность по противодействию экстремистской деятельности. На указанные подразделения приказом МВД России от 17 января 2006 г. № 19 возложены меры по предупреждению ПЭН. Одновременно приказом МВД России от 19 июня 2012 г. № 608 подразделениям по противодействию экстремизму предоставлено право на проведение полного перечня оперативно-розыскных мероприятий, предусмотренных Федеральным законом «Об оперативно-розыскной деятельности» от 12 августа 1995г. № 144-ФЗ. Приказом МВД России от 17 января 2006 г. № 19 на сотрудников подразделений по противодействию экстремизму возложены обязанности по предупреждению ПЭН и установлен перечень обязательных мероприятий проводимых для их предупреждения. Следует отметить, что организация и тактика проведения одного и того же ОРМ по различным ПЭН могут быть различны. При разработке рекомендаций о проведении отдельных ОРМ необходимо учитывать типичные характеристики личности (лица, совершающего ПЭН, которое может являться объектом проверки), включающей три компонента: социально-демографический и уголовно-правовой; особенности способа подготовки, совершения и сокрытия преступления; мотив совершения ПЭН.

2. Рекомендаџии по применению оперативно-профилактических мер при противодействии ПЭН. Оперативно-профилактические меры могут применяться оперативными сотрудниками совместно с общественными и другими негосударственными организациями, учреждениями и их представителями. Указанные меры разнообразны и зависят от вида экстремизма, сплоченности экстремистского сообщества и другого. Такие рекомендации следует разрабатывать исходя из следующих ситуаций применения различных мер: оперативно-профилактические меры противодействия молодежному экстремизму [2, с. 5155]; оперативно-профилактические меры противодействия экстремистским группам и сообществам. Можно выделять и другие ситуации при разработке направлений рекомендаций.

Так, при разработке рекомендаций по применению оперативно-профилактических мер противодействия молодежному экстремизму необходимо учитывать мнения специалистов учебных заведений, работающих с несовершеннолетними, возможности оперативно-поисковых подразделений и подразделений специальных технических мероприятий МВД России по сбору оперативно значимой информации и документированию противоправной деятельности молодежных объединений, в отношении которых имеются сведения об их причастности к экстремизму. 
Так, при обосновании рекомендаций по применению оперативно-профилактических мер противодействия экстремистским группам и сообществам необходимо знать информацию о деятельности экстремистских организаций, которая может быть получена, например, с использованием негласного аппарата, находящегося на связи с оперативными сотрудниками. Одной из оперативно-профилактических мер противодействия ПЭН является документирование противоправных действий на стадии подготовки экстремистских акций. В дальнейшем задокументированная с помощью специальных средств информация может позволить дестабилизировать и разобщить экстремистское сообщество и тем самым предотвратить планируемую экстремистскую акцию. Одним из направлений оперативно-профилактической работы также служит оперативная работа среди возможных объектов преступного посягательства, а именно в религиозных сообществах, исповедующих ислам или иудаизм, или среди иностранцев, прибывших по обмену на обучение в высших учебных заведениях. Отдельные оперативнопрофилактические меры проводятся в отношении лидеров экстремистских сообществ и их активных участников.

3. Рекомендации по взаимодействию с субъектами противодействия экстремизмy. Такие рекомендации следует разрабатывать исходя из ситуаций осуществления: внутреннего взаимодействия; внешнего взаимодействия.

Взаимодействие субъектов противодействия ПЭН является ключевым объектом в методике оперативно-розыскного противодействия ПЭН.

Внутреннее взаимодействие осуществляется между ОВД вышестоящими, подчиненными и равнозначными, а также между подразделениями территориальных ОВД на всех уровнях. Примером внутреннего взаимодействия среди подразделений территориальных органов является взаимодействие подразделений охраны общественного порядка с оперативными подразделениями. Так, в диспозицию статьи 282 УК РФ, предусматривающей ответственность за возбуждение ненависти либо вражды, а равно унижение человеческого достоинства из экстремистских мотивов внесено изменение, в части включения дополнительного условия для привлечения к уголовной ответственности, заключающегося в необходимости привлечения лица к административной ответственности за аналогичное деяние в течение одного года. Таким образом, следует, что с целью привлечения к уголовной ответственности необходимо наладить взаимодействие оперативных подразделений с подразделениями по охране общественного порядка в части предоставления оперативной информации для привлечения к административной ответственности за экстремистскую деятельность.

Еще одним примером внутреннего взаимодействия среди подразделений территориальных органов внутренних дел может служить взаимодействие оперативных подразделений экономической безопасности и противодействия коррупции и подразделений по противодействию экстремизму в части обмена оперативно-значимой информацией для подрыва экономической поддержки экстремистских организаций.

С целью противодействия экстремизму внешнее взаимодействие оперативных подразделений ОВД осуществляется с различными государственными органами, общественными, религиозными организациями и физическими лицами. Примером внешнего взаимодействия может служить содействие граждан, информирующих оперативные подразделения ОВД оперативно-значимой информацией, которая в последующем может оказать помощь в раскрытии преступления экстремистской направленности.

4. Рекомендачии по оперативной обстановке в регионе по ПЭН. Такие рекомендации необходимо обосновывать исходя из ситуаций, связанных с наиболее криминогенными регионами России, устанавливая взаимосвязь с количеством зарегистрированных ПЭН с социальными, национальными и демографическими факторами.

Наиболее криминогенными регионами по ПЭН являются Республика Дагестан и г. Москва [5].

В соответствии с перечнем некоммерческих организаций, в отношении которых судом принято вступившее в законную силу решение о ликвидации или запрете деятельности по ос- 
нованиям, предусмотренным Ф3 «О противодействии экстремистской деятельности», размещенном на официальном сайте Министерства юстиции России, в настоящее время на территории Российской Федерации запрещена деятельность 75 организаций, в том числе входящих в них структурных подразделений [4]. Также на указанном сайте размещен Федеральный список экстремистских материалов, в который внесены 5009 информационных материалов, признанных экстремистскими федеральным судом [7].

Между тем большинство скептиков полагают, что в связи с тем, что по данным статистики количество ПЭН по сравнению с общим числом зарегистрированных преступлений на территории России мало, оперативная обстановка в России является стабильной и не требует пристального внимания. Однако следует отметить, что количество зарегистрированных ПЭН ежегодно меняется. Одновременно повышенная общественная опасность указанных преступлений предполагает отсутствие необходимости сравнения с общим количеством зарегистрированных преступлений. Более того, даже совершение одного ПЭН может привести к дестабилизации обстановки в государстве, межнациональной и межконфессиональной вражде и тем самым привести к угрозе территориальной целостности Российской Федерации.

5. Рекомендаџии по использованию источников информачии по ПЭН. Необходимым условием эффективной работы правоохранительных органов является достоверная информация. Ее основные источники: «ведомственный обмен информацией между подразделениями органов внутренних дел; оперативная информация оперативных подразделений (ОУР, ЦПЭ); средства массовой информации, в частности сведения, размещенные в сети Интернет (интернет-ресурсы, интернет страницы); информационные материалы (печатные издания, листовки, видеофайлы, видеодиски, журналы и т. д.); информация, поступающая от других ведомств (Министерство просвещения, Министерство здравоохранения и т. д.); индивидуальная работа с уже выявленными лицами, причастными к экстремистской деятельности; иные правоохранительные органы: суд, прокуратура, ФМС, ФСИН и др.; об- щественные, религиозные организации, объединения, отдельные граждане» [3, с. 139-144]. Для грамотного и действенного противодействия ПЭН необходимо всем сотрудникам структурных подразделений в правоохранительной системе изучать и уметь определять принадлежность различных печатных изданий, видеоматериалов и листовок к экстремистским с целью дальнейшего запрета и распространения таких материалов. В связи с этим в рекомендациях необходимо отражать признаки экстремизма, возможности использования знаний специалистов, вопросы, на которые должен ответить специалист. Например, достаточно сложно установить лиц, распространяющих указанные материалы в глобальной информационной сети Интернет, так как распространение происходит дистанционно и установить в данном случае можно только IP-адрес персонального компьютера пользователя. Зачастую размещаемые материалы об общественных и межгосударственных конфликтах не соответствуют действительности или искажают реальные произошедшие события, имея цель разжечь межнациональную или межконфессиональную вражду. Необходимы рекомендации и по работе с интернет-сайтами, создаваемые запрещенными сообществами и призванными привлечь лиц к экстремистской деятельности. Все чаще можно встретить в социальных сетях «ВКонтакте», «Одноклассники», «Twitter», «Instagram», «Facebook» pa3мещенные картинки, видеозаписи, фотографии и комментарии, направленные на разжигание межнациональной вражды, на возбуждениененависти по отношению к Президенту, органам государственной власти России, политическим деятелям, российским гражданам и России в целом. Как показывает практика, виновные в размещении экстремистской информации лица проживают за территорией Российской Федерации и привлечь их к уголовной ответственности не представляется возможным.

\section{Выводы}

Разработка методики оперативно-розыскного противодействия преступлениям экстремистской направленности оперативными подразделениями органов внутренних дел, состоящей из комплекса ситуационно ориентирован- 
Методика оперативно-розыскного противодействия преступлениям экстремистской направленности

ных рекомендаций, имеет важное значение в выявлении, предупреждении и раскрытии преступлений. Вышеизложенные положения, характеризующие содержание отдельных методических рекомендаций, можно учитывать по противодействию различным видам экстремизма с учетом оперативно-розыскной характеристики конкретного вида преступлений, оперативной обстановки, складывающейся в регионе. Реализация ситуационного подхода при разработке комплекса методических рекомендаций позволяет сделать данную методику доступной и удобной для практического применения каждым оперативным сотрудником.

\section{СПИСОК ЛИТЕРАТУРЫ}

1. Давыдов, С. И. Ситуационный подход в теории и практике оперативно-розыскной деятельности органов внутренних дел : монография / С. И. Давыдов. - Барнаул : БЮИ МВД России, 2009. - 263 с.

2. Миронов, А. В. Оперативно-профилактические меры противодействия молодежному экстремизму / А. В. Миронов // Вестник Краснодарского Университета МВД России. - 2011. - № 2. - С. 51-55.

3. Паршина, И. А. Криминологический анализ эффективности деятельности подразделений органов внутренних дел по противодействию преступлениям экстремистской направленности / И. А. Паршина, И. Н. Чуб // Общество и право. - 2014. № 3 (49). - C. 139-144.

4. Перечень некоммерческих организаций, в отношении которых судом принято вступившее в законную силу решение о ликвидации или запрете деятельности по основаниям, предусмотренным Ф3 «О противодействии экстремистской деятельности». - Электрон. текстовые дан. - Режим доступа: https://minjust.ru/ru/nko/perechen_zapret (дата обращения: 30.01.2020). - Загл. с экрана.

5. Статистические сведения по преступлениям экстремисткой направленности. Официальные данные, предоставленные Порталом правовой статистики Генеральной прокуратуры РФ. - Электрон. текстовые дан. - Режим доступа: http:/crimestat.ru/ offenses_chart (дата обращения: 30.01.2020).

6. Уголовный кодекс Российской Федерации от 13 июня 1996 г. № 63-Ф3// Собрание законодательства Российской Федерации. - 1996. - № 25. - Ст. 2954.

7. Федеральный список экстремистских материалов. - Электрон. текстовые дан. - Режим доступа: https://minjust.ru/extremist-materials (дата обращения: 30.01.2020). - Загл. с экрана.

\section{REFERENCES}

1. Davydov S.I. Situatsionnyy podhod v teorii $i$ praktike operativno-rozysknoy deyatelnosti organov vnutrennikh del: monografiya [Situational Approach in the Theory and Practice of OperationalSearch Activities of Internal Affairs Bodies. A Monograph]. Barnaul, The Ministry of Internal Affairs of Russia, 2009. 263 p.

2. Mironov A.V. Operativno-profilakticheskiye mery protivodeystviya molodezhnomu ekstremizmu [Operational and Preventive Measures to Counteract Youth Extremism]. Vestnik Krasnodarskogo Universiteta MVD Rossii [Journal of Bulletin of The Krasnodar University Of The Ministry of Internal Affairs Of Russia], 2011, no. 2, pp. 51-55.

3. Parshina I.A., Chub I.N. Kriminologicheskiy analiz effektivnosti deyatelnosti podrazdeleniy organov vnutrennikh del po protivodeystviyu prestupleniyam ekstremistskoy napravlennosti [Criminological Analysis of the Effectiveness of the Activities of the Departments of the Internal Affairs Bodies in Countering Crimes of Extremist Orientation]. Obshchestvo i pravo [Journal of Society and Law], 2014, no. 3 (49), pp. 139-144.

4. Perechen nekommercheskikh organizatsiy, $v$ otnoshenii kotorykh sudom prinyato vstupivshee $v$ zakonnyyu silu reshenie o likvidatsii ili zaprete deyatelnosti po osnovaniyam, predusmotrenym FZ «O protivodeystvii ekstremistskoy deyatelnosti» [The List of Non-Profit Organizations in Respect of Which the Court has Adopted a Decision to Liquidate or Ban Activities on the Grounds Stipulated by the Federal Law "On Counteracting Extremist Activities"]. URL: https://minjust.ru/ru/nko/perechen_zapret (accessed 30 January 2020).

5. Statisticheskiye svedeniya po prestupleniyam ekstremistskoy napravlennosti. Ofitsialnyye dannye, predostavlennye Portalom pravovoy statistiki Generalnoy prokuratury $R F$ [Statistics on Extremist Crimes. Official Data Provided By The Portal of Legal Statistics of the Prosecutor General's Office of the Russian Federation]. URL: http://crimestat.ru/ offenses_chart (accessed 30 January 2020).

6. Ugolovnyy kodeks Rossiyskoy Federatsii ot 13 iyunya 1996 g. № 63-FZ [The Criminal Code of the Russian Federation of June 13, 1996, No. 63-FZ], Sobranie zakonodatelstva Rossiyskoy Federatsii [Collection of Legislation of the Russian Federation], 1996, no. 25, art. 2954.

7. Federalnyy spisok ekstremistskikh materialov [The Federal List of Extremist Materials]. URL: https://minjust.ru/extremist-materials (accessed 30 January 2020). 


\section{Information About the Authors}

Elena N. Kholopova, Doctor of Sciences (Jurisprudence), Professor, Department of Criminal Procedure, Criminalistics and Legal Informatics, Immanuel Kant Baltic Federal University, A. Nevskogo St., 14, 236016 Kaliningrad, Russian Federation, elchol@mail.ru, https://orcid.org/0000-0002-9077-1348

Yulia O. Kopchenkova, Junior Scientific Assistant, Department of Operational and Investigative Activities of the Internal Affairs Bodies, Saint Petersburg University of the Ministry of Internal Affairs of the Russian Federation, Letchika Pilyutova St., 1, 198206 Saint Petersburg, Russian Federation, uuu310@yandex.ru, https://orcid.org/0000-0002-5634-3227

\section{Информация об авторах}

Елена Николаевна Холопова, доктор юридических наук, профессор кафедры уголовного процесса, криминалистики и правовой информатики, Балтийский федеральный университет им. И. Канта, ул. А. Невского, 14, 236016 г. Калининград, Российская Федерация, elchol@mail.ru, https://orcid.org/0000-0002-9077-1348

Юлия Олеговна Копченкова, адъюнкт кафедры оперативно-разыскной деятельности в органах внутренних дел, Санкт-Петербургский университет Министерства внутренних дел Российской Федерации, ул. Летчика Пилютова, 1, 198206 г. Санкт-Петербург, Российская Федерация, uuu310@yandex.ru, https://orcid.org/0000-0002-5634-3227 